\title{
Transmission Competency of Single-Female Xiphinema index Lines for Grapevine fanleaf virus
}

\author{
Gérard Demangeat, Véronique Komar, Cyril Van-Ghelder, Roger Voisin, \\ Olivier Lemaire, Daniel Esmenjaud, and Marc Fuchs
}

First, second, and fifth authors: Institut National de la Recherche Agronomique-Université de Strasbourg. UMR 1131, SVQV 'Santé de la Vigne et Qualité du Vin', 28 rue de Herrlisheim, BP20507, 68000 Colmar, France; third, fourth, and sixth authors: Institut National de la Recherche Agronomique, UMR 6243, IBSV 'Interactions Biotiques et Santé Végétale' Laboratoire de Nématologie, 400 route des Chappes, 06903 Sophia Antipolis, France; and seventh author: Department of Plant Pathology and Plant-Microbe Biology, Cornell University, New York State Agricultural Experiment Station, Geneva, NY 14456.

Accepted for publication 23 December 2009.

\begin{abstract}
Demangeat, G., Komar, V., Van-Ghelder, C., Voisin, R., Lemaire, O., Esmenjaud, D., and Fuchs, M. 2010. Transmission competency of singlefemale Xiphinema index lines for Grapevine fanleaf virus. Phytopathology 100:384-389.

Grapevine fanleaf virus (GFLV) is vectored specifically from grapevine to grapevine by the ectoparasitic nematode Xiphinema index. Limited information is available on the vector competency of $X$. index populations from diverse geographical origins. We determined the transmissibility of two GFLV strains showing 4.6\% amino acid divergence within their coat protein (e.g., strains F13 and GHu) by seven clonal lines of $X$. index developed from seven distinct populations from the Mediterranean basin (Cyprus, southern France, Israel, Italy, and Spain), northern France, and California. $X$. index lines derived from
\end{abstract}

ABSTRACT single adult females were produced on fig (Ficus carica) plants to obtain genetically homogenous aviruliferous clones. A comparative reproductive rate analysis on Vitis rupestris du Lot and V. vinifera cv. Cabernet Sauvignon showed significant differences among clones, with the singlefemale Cyprus line showing the highest rate (30-fold the initial population) and the Spain and California lines showing the lowest rate (10-fold increase), regardless of the grapevine genotype. However, there was no differential vector competency among the seven $X$. index lines for GFLV strains F13 and GHu. The implications of our findings for the dynamic of GFLV transmission in vineyards and screening of Vitis spp. for resistance to GFLV are discussed.

Additional keywords: longidorid.
Grapevine fanleaf virus (GFLV) is responsible for fanleaf degeneration, the most severe viral disease of grapevines worldwide. This virus reduces vigor, crop yield (up to 80\%), and fruit quality (1). It also reduces the lifespan of vineyards and can cause plant mortality (1). GFLV belongs to the genus Nepovirus in the family Secoviridae, subfamily Comovirinae. It is specifically transmitted from grapevine to grapevine by the soilborne longidorid ectoparasitic nematode Xiphinema index. GFLV has a bipartite genome consisting of two single-stranded RNA molecules, each encoding for a polyprotein, which are cleaved by the viral protease into mature proteins (Fig. 1). RNA1 encodes proteins involved in viral replication and polyprotein maturation whereas RNA2 encodes a protein involved in replication $\left(2 \mathrm{~A}^{\mathrm{HP}}\right)$, the movement protein $\left(2 \mathrm{~B}^{\mathrm{MP}}\right)$, and the coat protein $\left(2 \mathrm{C}^{\mathrm{CP}}\right)$. The coat protein of GFLV is responsible for the specificity of transmission by $X$. index $(2,4)$. GFLV isolates differing by 0.2 to $6.9 \%$ at the amino acid level have been identified (42).

GFLV and $X$. index have an almost worldwide distribution $(1,39)$. It is hypothesized that $X$. index originated from the Middle East, where it is found in natural woodlands associated with grapevines (30). From this area, $X$. index and GFLV probably spread to most grapevine-growing regions of the world via the Mediterranean basin through rooted propagation material. Results of a recent phylogeoagraphical study based on genetic diversity of

Corresponding author: G. Demangeat;

E-mail address: gerard.demangeat@ colmar.inra.fr

doi:10.1094/PHYTO-100-4-0384

(C) 2010 The American Phytopathological Society the $X$. index cytochrome B gene $(c y t B)$ were consistent with this hypothesis (44). Indeed, analyses of $c y t B$ nucleotide substitution pattern of $X$. index from diverse geographical origins revealed that all the haplotypes identified were present in populations from Cyprus, Israel, Palestine, and Iran whereas populations from America (Chile and the United States) and Europe (France, Greece, Italy, and Spain) had only one of the haplotypes identified. These results suggested that $c y t B$ haplotype distribution paralleled the history of grapevine cultivation (44).

$X$. index has a narrow host range, with grapevine as the major natural host $(1,39)$. The reproduction rate of $X$. index varies with the grapevine genotypes $(15,28)$. For example, a high rate was achieved on Vitis riparia Gloire de Montpellier and SO4 (V. berlandieri $\times V$. riparia) but a low rate on Freedom ([V. longii $\times$ Othello $\times$ Dogridge) and 161-49 Couderc (V. riparia $\times$ V. berlandieri) (28). Rootstocks with Muscadinia rotundifolia parentage are resistant to $X$. index feeding $(5,20,47,48)$. However, the nematode can probe and transmit GFLV to $X$. index-resistant rootstocks. Therefore, virus translocation occurs from $X$. index-resistant rootstocks into scions, although the debilitating effects of fanleaf degeneration are reduced $(47,48)$. For most susceptible grapevine genotypes, the feeding process of $X$. index on actively growing roots causes malformation, swelling, galling, or necrosis of grapevine root tips. Fig (Ficus carica) is another host for $X$. index but fig is not a host for GFLV $(32,40)$.

$X$. index reproduces parthenogenetically, although a sexual reproduction may occur occasionally in spite of rare males (16). A single female is able to reproduce and generate a clonal lineage $(15,32)$. Eggs are laid in the spring and develop into adults through four juvenile stages. The life cycle of $X$. index lasts from 
one to several months depending on biotic and abiotic factors $(3,39)$. X. index, including viruliferous specimens, can survive for at least 4 years when stored in vineyard soil in the absence of host plants (18) and for 4.5 years in a fallowed vineyard (33).

Nematodes from distinct geographical origins can differ in their efficiency of virus transmission. For example, $X$. diversicaudatum populations from France, Italy, and Spain transmitted Arabis mosaic virus (ArMV) poorly, whereas populations from Bulgaria, England, New Zealand, Norway, Scotland, Switzerland, and the United States were efficient vectors of ArMV (6,7). A similar situation applies to Longidorus arthensis, the specific vector of Cherry rosette virus (CRV), for which populations from four regions in Switzerland (Arth, Rossberg, Steinberg, and Talmatte) transmitted CRV efficiently whereas populations from two other regions (Baselland and Maiberg) did not vector CRV (9). Limited information is available for $X$. index and GFLV. Studying the vector competency of geographically diverse $X$. index populations would provide useful information into virus-vector relationships and fanleaf epidemiology. The transmission of GFLV by different $X$. index populations was reported earlier (12-14). However, the low number of $X$. index populations studied and their restricted geographical diversity precluded any conclusions on the effect of the origin of $X$. index on GFLV transmission competency. Also, the transmission procedure was not optimal for comparative transmissibility assays $(12,14)$.

We evaluated the transmission competency of seven $X$. index lines of different geographical origins by using two genetically distinct GFLV strains. Single-female lines were produced for each population and their multiplication rate was analyzed on two Vitis spp. Here, we report a similar competency of acquisition and transmission of the two GFLV strains by the seven single-femalederived $X$. index lines despite different multiplication rates. The implications of these findings for the GFLV spread in vineyards and screening of Vitis spp. for GFLV resistance are discussed.

\section{MATERIALS AND METHODS}

Virus strains. GFLV strains F13 (46) and GHu (25) were isolated from naturally infected $V$. vinifera cvs. Muscat de Frontignan and Gloriae Hungariae, respectively. Sequences of GFLVF13 and GFLV-GHu RNA2 were determined previously $(34,35,43)$ and obtained from GenBank accession numbers X16907, D00915, and EF426852. GFLV-F13 and -GHu were transferred by mechanical inoculation from infected grapevine leaf tissue to Chenopodium quinoa and propagated in this systemic herbaceous host. GFLV-F13 and -GHu were back trans-
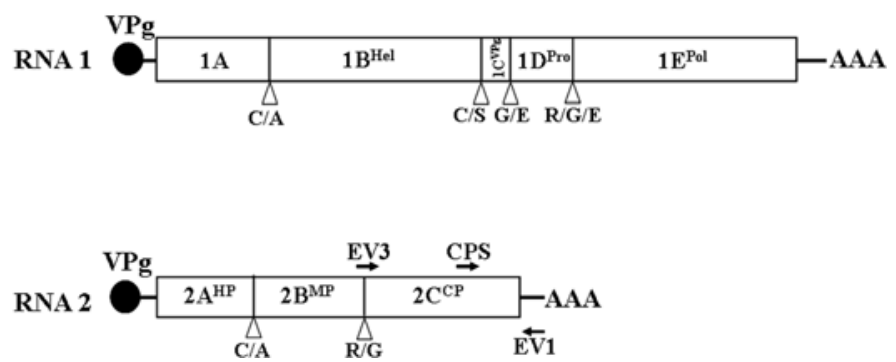

Fig. 1. Genome organization and expression of Grapevine fanleaf virus (GFLV). Open boxes represent open reading frames encoded by the two genomic RNAs. The 5' and 3' untranslated regions are denoted by a black line, the viral protein genomic (VPg) is represented by a black circle and the cleavage sites are indicated by arrows below the polyproteins. Processed proteins encoded by the two genomic RNAs are indicated within the polyproteins: $1 \mathrm{~A}$, putative proteinase cofactor; $1 \mathrm{~B}^{\mathrm{Hel}}$, putative helicase; $1 \mathrm{C}^{\mathrm{VPg}}$, $\mathrm{VPg}$; $1 \mathrm{D}^{\text {Pro }}$, proteinase; $1 \mathrm{E}^{\mathrm{Pol}}$, putative RNA-dependant RNA polymerase; $2 \mathrm{~A}^{\mathrm{HP}}$, homing protein; $2 \mathrm{~B}^{\mathrm{MP}}$, movement protein; and $2 \mathrm{C}^{\mathrm{CP}}$, coat protein. The position of primers CPS, EV1, and EV3 used to detect GFLV by immunocapture (IC) reverse-transcription polymerase chain reaction (RT-PCR) or RT-PCR assays is indicated. mitted onto the certified, virus-tested rootstock Kober 5BB ( $V$. berlandieri $\times V$. riparia) clone 259 by in vitro heterologous grafting, as described previously (4).

Plant material. Fig ( $F$. carica) plants were used to produce single-female-derived $X$. index lines and establish rearings of aviruliferous $X$. index. Fig plants were produced either by in vitro multiplication (26) or propagation of green cuttings on rockwool (Grodan, Roermond, The Netherlands) in a growth chamber under controlled temperature $\left(20\right.$ to $\left.26^{\circ} \mathrm{C}\right)$ and light (16-h photoperiod and $60 \mu$ Einstein $/ \mathrm{m}^{2} / \mathrm{s}$ ) conditions.

$V$. rupestris du Lot and V. vinifera cv. Cabernet Sauvignon were used to determine the reproduction rate of single-female $X$. index lines. Plants of the two grapevine genotypes were micropropagated in vitro and acclimatized in a greenhouse (41).

Healthy and GFLV-F13- or -Ghu-infected grapevine rootstock Kober 5BB were used in nematode transmission experiments as virus recipient and virus donor plants, respectively. Healthy and virus-infected rooted Kober $5 \mathrm{BB}$ plants were produced from green cuttings (17).

Production and multiplication of single-female-derived $X$. index lines. Seven $X$. index populations from naturally GFLVinfected vineyards were collected and maintained on grapevines in a greenhouse at the Institut National de la Recherche Agronomique (INRA) in Sophia-Antipolis, France (Table 1). For each population, single-female lines were obtained by transferring a single adult female into a $200-\mathrm{ml}$ container planted with one rooted fig plant produced in vitro. After 1 year, nematode specimens were isolated using an Oostenbrink elutriator and a Baermann funnel (24). Females and the four juvenile stages were identified following morphometric $X$. index characteristics (27). Specimens of each $X$. index line were transferred into 10-liter containers planted with fig plants and cultured in a greenhouse to increase population density. Increased single-female $X$. index clonal lines progeny were used in this study.

Determining the multiplication rate of $X$. index lines. Rooted cuttings of $V$. rupestris and $V$. vinifera were micropropagated in vitro and planted in sandy soil in 2-liter containers in a greenhouse. Vines showing homogenous growth were selected and their roots were exposed to 250 aviruliferous single-female-derived $X$. index that were extracted from soil samples recovered from containers planted with fig using an Oostenbrinck elutriator and a Baermann funnel (24). Five to eight replicates were used per grapevine cultivar and single-female $X$. index line combinations. After 5 months of cultivation, the soil of each 2-liter container was recovered in 10-liter buckets and plant roots were carefully washed using tap water and dried. Roots were collected and weighted, and $X$. index were extracted from the water suspension based on an adapted Oostenbrink method (24). Nematodes were counted with a stereomicroscope to determine their total number per plant. The ratio of the total number of $X$. index recovered (final population [fp]) over the initial number of $X$. index (initial population [ip]) was calculated to determine the multiplication rate (fp/ip) for each nematode line.

GFLV transmission by single-female-derived $X$. index lines. The vector transmissibility of GFLV-F13 and -GHu was determined using aviruliferous single-female-derived $X$. index lines

TABLE 1. Origin of the Xiphinema index populations collected from vineyards naturally infected by Grapevine fanleaf virus (GFLV) and used to produce single-female lines

\begin{tabular}{lll}
\hline Line ID & Country & Region \\
\hline Cyprus & Cyprus & Unknown \\
Israel & Israel & Unknown \\
Italy & Italy & Apulia \\
France-1 & France & Champagne \\
France-2 & France & Provence \\
Spain & Spain & South Mancha \\
California & United States & Napa Valley \\
\hline
\end{tabular}


reared on fig, as described previously (4). Transmission experiments used a two-step procedure with infected rooted Kober 5BB grapevines as donors and rooted healthy Kober 5BB grapevines as recipients. Two repetitions with 10 to 14 individual transmission assays were run per GFLV strain and single-female $X$. index line. The transmissibility of GFLV isolates was assessed by doubleantibody sandwich (DAS) enzyme-linked immunosorbent assay (ELISA) using root samples of recipient grapevines $(4,6)$. The systemic GFLV infection of recipient grapevines was analyzed by DAS-ELISA in newly emerging leaves after a cold treatment.

GFLV detection in $X$. index by reverse transcription-polymerase chain reaction. The presence of GFLV was assessed in groups of $20 \mathrm{X}$. index by reverse-transcription polymerase chain reaction (RT-PCR) using primers specific to GFLV-F13 RNA2 (17). The RT reaction used 50 pmol of reverse primer EV1 (5' ${ }^{3574}$ GACTATCTAGACACATATATACACTTGGGTCTTTTAA ${ }^{3601}$ $3^{\prime}$ ) (Fig. 1) with an additional XbaI site underlined. The PCR reaction was performed in a final volume of $50 \mu$ l containing $10 \mu \mathrm{l}$ of the RT reaction and $50 \mathrm{pmol}$ of primers EV1 and CPS $\left(5^{\prime}\right.$ ${ }^{3045}$ TTGTGCGCCCAGATCTCTCTTTACCA ${ }^{3070} 3^{\prime}$ ) (Fig. 1) in a Master thermocycler (Eppendorf, Hamburg, Germany). RT-PCR products were analyzed under UV illumination following electrophoresis on $1 \%$ agarose gels and ethidium bromide staining.

GFLV detection in grapevines by DAS-ELISA and immunocapture RT-PCR restriction fragment length polymorphism. GFLV was detected in leaf and root samples of individual vines by DAS-ELISA using specific antibodies as described $(4,6)$. The antibodies used in DAS-ELISA recognized equally GFLV strains $\mathrm{F} 13$ and $\mathrm{GHu}$. The full-length $2 \mathrm{C}^{\mathrm{CP}}$ gene of GFLV was further characterized by immunocapture (IC)-RT-PCR using root samples of recipient grapevines that reacted positively in DAS-ELISA and primers EV1 and EV3 $(42,43)$. IC-RT-PCR-amplified DNA products were purified from agarose gels using the QIAquick extraction kit following the supplier's instructions (Qiagen, Hilden, Germany) and characterized by restriction fragment length polymorphism (RFLP) using EcoRI and StyI digestion to discriminate the two GFLV strains (42). IC-RT-PCR and RFLP products were resolved by electrophoresis on $1 \%$ agarose and $7 \%$ polyacrylamide gels, respectively, and analyzed after ethidium bromide staining using a UV light transilluminator.

Statistical analyses. Data collected on $X$. index multiplication rates on two grapevine genotypes and GFLV transmission assays were processed for statistical analysis. Multiplication rates were subjected to analysis of covariance, for which nematode lines and grapevine genotype were factors studied. Root weight was used as covariate. Comparisons of means were done using a "Dunnett" test with the single-female $X$. index line France-2 as reference, because it is used routinely in transmission experiments at INRA in Colmar, France. The transmission rates were subjected to analysis of variance using line and genotype as fixed factors. In order to satisfy hypotheses of normality of the residuals and homoscedasticity of the variances, multiplication and transmission rates were log and square-root transformed, respectively, and hypotheses were tested using a Shapiro-Wilk normality test and a studentized Breusch-Pagan test, respectively. Statistical analyses were run using $\mathrm{R}$ package (The $\mathrm{R}$ Project for Statistical Computing, version 2.8.1, available at http://www.r-project.org/).

\section{RESULTS}

Individual adult females were isolated from seven $X$. index populations collected from various vineyards in the Mediterranean basin (Cyprus, southern France, Israel, Italy, and Spain), northern France, and California (Table 1). Individual $X$. index females were deposited on roots of young fig plants and nematodes derived from a single adult female were further increased on rooted fig plants to obtain genetically homogenous aviruliferous clonal lines for comparative reproduction assays and GFLV transmission experiments.

The reproduction rate of groups of $250 \mathrm{X}$. index individuals from single-female lines reared on fig was determined on $V$. rupestris and $V$. vinifera. Multiplication ratios were positive for all $X$. index lines after 5 months of culture in a greenhouse (Table 2), indicating that the seven single-female lines multiplied on the two grapevine genotypes. However, the multiplication rate varied among the seven lines, regardless of the grapevine genotype. Analysis of covariance (type III) showed that the multiplication rate was strongly linked to the $X$. index line $(F=13.88$; Df $=6$; $P<0.0001)$. The effect of grapevine genotype $(F=0.0171 ; \mathrm{Df}=$ $1 ; P=0.75)$, grapevine root weight $(F=0.0004 ; \mathrm{Df}=1 ; P=0.98)$ and line-genotype interaction $(F=1.11$; Df $=6 ; P=0.37)$ were not significant (Table 2). Considering only single-female $X$. index lines as factor, hypotheses of normality of the residuals (ShapiroWilk test: $\mathrm{W}=0.99, P=0.82$ ) and homoscedasticity of the variances (Breusch-Pagan test: $\mathrm{BP}=7.526$; $\mathrm{Df}=6 ; P=0.275$ ) were satisfied. The multiplication rate of the Cyprus single-female line was approximately three times higher compared with the Spain and California single-female lines, while other lines showed intermediary multiplication ratios (Table 2). A comparison of means (Dunnett Test) indicated that the Cyprus, Spain, and California lines were significantly different from France- 2 whereas the three others lines (France-1, Italy, and Israel) were not significantly different from France-2 (Table 2).

The transmissibility of GFLV strains F13 and GHu by aviruliferous nematodes of the seven $X$. index single-female lines was determined. GFLV strains F13 and GHu were selected for comparative transmission assays because their coat proteins, which are involved in transmission specificity (4), have $4.6 \%$ amino acid divergence. Prior to initiating the nematode transmission tests, the presence of GFLV was confirmed in roots of source grapevines by

TABLE 2. Multiplication of single-female Xiphinema index lines on Vitis rupestris cv. du Lot and V. vinifera cv. Cabernet Sauvignon, and root weight of grapevine hosts

\begin{tabular}{|c|c|c|c|c|c|c|c|c|}
\hline \multirow[b]{2}{*}{$X$. index line } & \multicolumn{3}{|c|}{ V. vinifera $\mathrm{cv}$. Cabernet } & \multicolumn{3}{|c|}{ V. rupestris du Lot } & \multicolumn{2}{|c|}{$\log (f p / i p)^{a}$} \\
\hline & $\mathrm{fp}^{\mathrm{b}}$ & $\mathrm{fp} / \mathrm{ip}^{\mathrm{c}}$ & $\operatorname{Root}(\mathrm{g} / \text { vine })^{\mathrm{d}}$ & $\mathrm{fp}^{\mathrm{b}}$ & $\mathrm{fp} / \mathrm{ip}^{\mathrm{c}}$ & Root $(\mathrm{g} / \text { vine })^{\mathrm{d}}$ & Means & Standard errol \\
\hline Cyprus & 7,573 & 30.3 & 43.4 & 7,525 & 30.1 & 42 & $3.332 * * *$ & 0.115 \\
\hline Israel & 3,225 & 12.9 & 49.8 & 4,150 & 16.6 & 43 & 2.606 & 0.111 \\
\hline France-1 & 3,896 & 15.6 & 50 & 5,005 & 20 & 37 & 2.876 & 0.111 \\
\hline France-2 & 4,409 & 17.6 & 38 & 3,846 & 15.4 & 37 & 2.666 & 0.107 \\
\hline Spain & 1,982 & 7.9 & 47 & 2,303 & 9.2 & 40 & $2.163 * *$ & 0.103 \\
\hline
\end{tabular}

${ }^{a}$ Data represent the means of the multiplication rates log transformed for each line; $\mathrm{fp}=$ final population and ip = initial population. Statistically different means at $P \leq 0.05,0.01$, and 0.001 indicated by *,**, and ***, respectively, using Dunnett's test are indicated.

${ }^{\mathrm{b}}$ Data represent the total number of $X$. index recovered after 5 months of culture (fp). Five to eight plants were used for each combination of $X$. index line and genotype.

c Ratio of the total number of $X$. index recovered after 5 months of culture over the initial number of $X$. index exposed to grapevine roots (ip $=250$ ).

${ }^{\mathrm{d}}$ Data represent root weight mean after 5 months of contact with nematodes. 
DAS-ELISA (data not shown). For transmission tests, 300 aviruliferous nematodes were exposed to roots of GFLV-infected grapevine plants for 6 weeks. After completion of the virus acquisition step, virus source plants were uprooted and replaced by healthy grapevines. Nematodes were then allowed to feed for six additional weeks. Results from two independent experiments indicated that the seven single-female lines transmitted both GFLV strains with a mean rate of $93 \%$ (321 infected out of 344 grapevines tested) (Table 3 ). These data were consistent with the notion that GFLV transmission is not influenced by the geographical origin of $X$. index. Analysis of variance (ANOVA type III) showed that the effect of $X$. index lines $(F=0.59$; Df $=6 ; P=0.74)$, GFLV strains $(F=0.18$; Df $=1 ; P=0.67)$, and line-GFLV strain interaction $(F=0.39 ; \mathrm{Df}=6 ; P=0.87)$ on transmission rate were not significant. A model, including lines and GFLV strains as factors, satisfied the hypothesis of the normality of the residuals (Shapiro-Wilk test: $\mathrm{W}=0.97 ; P=0.51$ ) and the homoscedasticity of the variance (Breusch-Pagan test: $\mathrm{BP}=9.96$; $\mathrm{Df}=7 ; P=0.191$ ).

To validate transmission results, three criteria of the nematode transmission process described by Brown and Weischer (11) were verified. First, grapevine roots were examined for malformation as indicative of nematode feeding. Roots of the majority of source $(89 \%, 336$ of 378) and recipient $(93 \%, 320$ of 344) grapevines showed galls or swelling, indicating that the seven $X$. index lines were actively feeding. Second, the viruliferous status of nematodes was determined after the acquisition step. GFLV-F13 and -GHu were detected in $X$. index by RT-PCR using total nematode RNA extracted from randomly selected samples of 20 adult nematodes (Fig. 2). A specific DNA fragment of the expected size (566 bp) was obtained for all the $X$. index tested (Fig. 2A and B). These results showed that some specimens of the seven single-

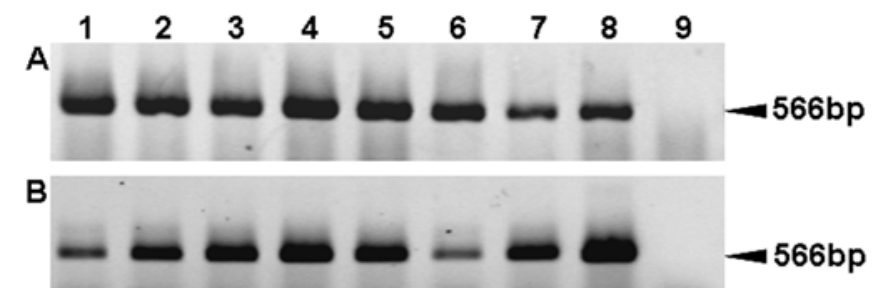

Fig. 2. Reverse transcription-polymerase chain reaction (RT-PCR) detection of A, Grapevine fanleaf virus (GFLV)-F13 and B, GFLV-GHu in Xiphinema index after the acquisition step. Total RNA were extracted from samples of 20 nematodes isolated from single-female lines from Cyprus (lane 1), Israel (lane 2), Italy (lane 3), France-1 (lane 4), France-2 (lane 5), Spain (lane 6), and the United States (lane 7). Lanes 8 and 9 correspond to RT-PCR products of 20 nematodes reared on GFLV-F13-infected and healthy grapevines, respectively. RT-PCR products were analyzed by electrophoresis on $1 \%$ agarose gels and staining with ethidium bromide.

TABLE 3. Transmission rate of Grapevine fanleaf virus (GFLV) strains F13 and $\mathrm{GHu}$ by seven single-female Xiphinema index lines from diverse geographical origins

\begin{tabular}{lcccccccc}
\hline & \multicolumn{2}{c}{ GFLV-F13 } & & \multicolumn{2}{c}{ GFLV-GHu } & & \multicolumn{2}{c}{ Mock } \\
\cline { 2 - 3 } \cline { 8 - 9 } X. index line & Ratio & $\%$ & & Ratio & $\%$ & & Ratio & $\%$ \\
\hline Cyprus & $22 / 24$ & 92 & & $23 / 24$ & 96 & & $0 / 9$ & 0 \\
Israel & $24 / 26$ & 92 & & $22 / 24$ & 92 & & $0 / 10$ & 0 \\
Italy & $25 / 26$ & 96 & & $23 / 24$ & 96 & & $0 / 10$ & 0 \\
France-1 & $24 / 22$ & 92 & & $21 / 24$ & 88 & & $0 / 10$ & 0 \\
France-2 & $23 / 26$ & 88 & & $23 / 24$ & 96 & & $0 / 8$ & 0 \\
Spain & $22 / 24$ & 92 & & $23 / 24$ & 96 & & $0 / 9$ & 0 \\
United States & $25 / 26$ & 96 & & $23 / 24$ & 96 & & $0 / 10$ & 0 \\
Total & $163 / 176$ & 93 & & $158 / 168$ & 94 & & $0 / 66$ & 0 \\
\hline
\end{tabular}

${ }^{a}$ Data represent the total number of bait grapevines infected by GFLV, as shown by double-antibody sandwich enzyme-linked immunosorbent assay, following $X$. index-mediated transmission over the total number of bait grapevines used in transmission assays. Data from two independent transmission experiments with 10 to 14 plants each were pooled. female lines acquired GFLV. In addition, none of the bait grapevines was infected by GFLV after exposure to $X$. index from fig plants (Table 3 ), indicating that the seven single-female lines were aviruliferous when reared on fig. Third, the genetic integrity of the GFLV strains was analyzed after transmission by characterizing the coding region of the $2 \mathrm{C}^{\mathrm{CP}}$ gene in leaves of infected recipient grapevines by IC-RT-PCR using primers EV1 and EV3 (Fig. 1). The $2 \mathrm{C}^{\mathrm{CP}}$ amplicons obtained had the expected DNA size fragment (1,573 bp) (Fig. 3A and D, lanes 1 to 7$)$ and co-migrated with DNA fragments amplified from infected source grapevines (Fig. 3A and D, lane 8). RFLP analysis of purified $2 \mathrm{C}^{\mathrm{CP}}$ amplicons showed the expected banding patterns for GFLV-F13 with 1,075-, 330-, and 168-bp EcoRI fragments (Fig. 3B) and 690-, 350-, 276-, and 110-bp StyI fragments (Fig. 3C) for all the recipient grapevines tested as well as one source grapevine. Similarly, the expected RFLP patterns for the GFLV-GHu $2 \mathrm{C}^{\mathrm{CP}}$ gene were obtained from recipient grapevines with undigested EcoRI products (Fig. 3E) and 510-, 394-, 350-, and 276-bp StyI fragments (Fig. 3F) from all recipient and source grapevines tested. These results confirmed that the seven $X$. index lines acquired and transmitted GFLV strains F13 and GHu.

\section{DISCUSSION}

The transmission competency of seven $X$. index lines from diverse geographical origins was determined with two genetically divergent GFLV strains. Although the seven nematode lines showed differences in their reproductive rate on two Vitis spp., they vectored the two GFLV strains with a 93\% mean transmission rate regardless of their country of origin. These results clearly indicated no geographical competency of $X$. index for GFLV transmission.

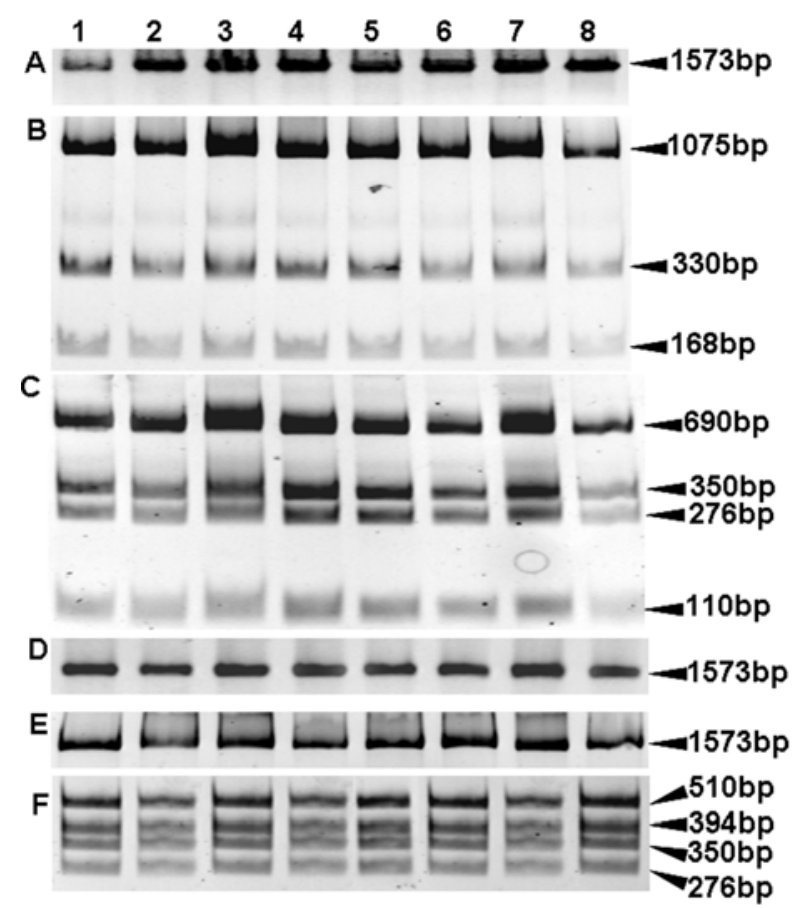

Fig. 3. Characterization of the coat protein $\left(2 \mathrm{C}^{\mathrm{CP}}\right)$ gene of Grapevine fanleaf virus (GFLV) strains after Xiphinema index transmission. The $2 \mathrm{C}^{\mathrm{CP}}$ gene was amplified by immunocapture reverse-transcription polymerase chain reaction from infected bait grapevines exposed to single- female $X$. index lines from Cyprus (lane 1), Israel (lane 2), Italy (lane 3), France-1 (lane 4), France-2 (lane 5), Spain (lane 6), and the United States (lane 7). A and D, Amplicons of the $2 \mathrm{C}^{\mathrm{CP}}$ gene were digested by $\mathbf{B}$ and $\mathbf{E}$, EcoR1 and $\mathbf{C}$ and $\mathbf{F}$, StyI, respectively. Restriction fragment length polymorphism patterns obtained from bait plants were compared with those from source plants infected with either A to C, GFLV-F13 (lane 8) or D to F, GFLV-GHu (lane 8). DNA fragments less than $100 \mathrm{bp}$ are not visible. 
Previous studies reported an efficient transmission of GFLV isolates by different populations of $X$. index (12-14). However, the impact of the geographical origin could not be investigated rigorously because the number of $X$. index populations and their geographical diversity were limited. Also, the transmission procedure was not designed for comparative evaluations because it did not rely on a standardized protocol. In our study, $X$. index origins were chosen to represent a broad geographical diversity, with populations from Europe (mainly from Mediterranean countries), the Middle East, and North America. Also, a standardized procedure was used to assess the transmissibility of GFLV strains with a single Vitis genotype (e.g., Kober 5BB) as source and bait plants. Furthermore, the susceptibility of Kober 5BB to $X$. index feeding and GFLV transmission is similar to that of $V$. rupestris, one of the grape genotypes used in our study to assess multiplication rates $(15,36)$. This similarity enabled us to make inferences between the multiplication rate and vector competency of the seven $X$. index lines. Moreover, $X$. index lines representing genetically homogenous material were used for optimal comparative transmission assays. Altogether, our experimental conditions enabled us to compare the competency of different $X$. index lines for GFLV transmission. To our knowledge, this is the first in-depth evaluation on a possible association between the geographical origin of $X$. index and its GFLV vectoring capacity. It would have been interesting to investigate the transmissibility of the two GFLV strains used in this study with lower numbers of $X$. index, as reported previously for ArMV and X. diversicaudatum (7), Grapevine leafroll-associated virus 3 and mealybugs (19), and Zucchini yellow mosaic virus and Myzus persicae (38), among other examples. Unfortunately, reliable GFLV transmission assays require at least $300 \mathrm{X}$. index individuals, as shown by several investigators $(2,4,14,36,37)$, although a single viruliferous individual can be vector competent (D. Esmenjaud, unpublished data).

The seven $X$. index lines used in our study transmitted the two divergent GFLV isolates at similar rates. This situation contrasts with the lack of transmission of strains of ArMV and Strawberry latent ringspot virus (SLRV) by some $X$. diversicaudatum populations $(6-8,10)$. A difference in vector capacity and efficiency between $X$. diversicaudatum and $X$. index, two closely related dagger nematode species, is likely associated with their host range. $X$. diversicaudatum has a broad host range whereas $X$. index has a narrow host range (39). Both Xiphinema spp. vary also in their reproduction mode. The amphimictic reproduction of $X$. diversicaudatum underlies a higher genetic variability that may explain differences in vector capacity. To this extent, a loss in transmission efficiency was reported in progenies from two $X$. diversicaudatum populations (8). Because $X$. index mainly reproduces by meiotic parthenogenesis, a loss of GFLV vector capacity among progenies is less likely to occur.

The reproduction rate of the seven single-female $X$. index lines characterized in this study varied considerably. Variations were not linked to grapevine root vigor or grapevine genotype but to $X$. index lines. However, differences in reproduction rate were not associated with differences in the ability to transmit the two GFLV strains. Probing behavior or genetic factors of $X$. index lines could account for differential reproduction rates. More work is needed to verify these hypotheses. A difference between reproduction and virus vectoring capacity was described for $X$. diversicaudatum populations of different geographical origin (10).

Nematode transmission of viruses is characterized by the vector's ability to acquire and retain virus particles at specific sites within the feeding apparatus and, subsequently, release them into a recipient plant (11). $X$. diversicaudatum populations that are poor vectors or fail to transmit viruses do not efficiently retain ArMV or SLRV particles (10). Our experimental data indicated that the two GFLV isolates were equally acquired and retained by the seven single-female lines, because GFLV $2 \mathrm{C}^{\mathrm{CP}}$ amplicons were clearly detected in all the nematodes randomly recovered and tested after the acquisition step. Similarly, GFLV $2 \mathrm{C}^{\mathrm{CP}}$ amplifiable DNA products were obtained in the root zone of bait grapevine plants at the end of the transmission experiments.

$X$. index is considered to be the only natural vector of GFLV $(1,12,28,39)$. A strong and specific interaction characterizes the association between $X$. index and GFLV. Indeed, $X$. index can retain GFLV for at least 4 years (18). Based on our findings with seven $X$. index lines from diverse geographical locations, it is reasonable to anticipate that most, if not all, $X$. index populations are able to transmit natural GFLV isolates. This hypothesis is also supported by the fact that no natural nontransmissible GFLV isolate has been recovered from naturally infected vineyards. This is in contrast with SLRV isolates not transmitted by several $X$. diversicaudatum populations; Tomato ringspot virus strains differentially transmitted by populations of $X$. americanum, X. bricolensis, $X$. californicum, and $X$. rivesi (39); and Tobacco rattle virus isolates differentially transmitted by Paratrichodorus pachydermus nematodes (31). Our observations on GFLV confirm the strong genetic stability of its coat protein (42) and support a strong selection pressure on the corresponding gene to conserve the potential to be transmitted by $X$. index.

GFLV is exclusively transmitted by $X$. index whereas ArMV is specifically transmitted by $X$. diversicaudatum $(11,29)$. The transmissibility of chimeric viruses for which the $2 \mathrm{~A}^{\mathrm{HP}}, 2 \mathrm{~B}^{\mathrm{MP}}$, or $2 \mathrm{C}^{\mathrm{CP}}$ genes of GFLV were replaced by their ArMV counterpart sequences have shown that protein $2 \mathrm{C}^{\mathrm{CP}}$ is the sole viral determinant responsible for the specific transmission of $\operatorname{GFLV}(2,4)$. Recently, GFLV-GHu was shown to result from three interspecies recombination events between GFLV and ArMV with gene $2 \mathrm{~B}^{\mathrm{MP}}$ of ArMV origin and gene $2 C^{\mathrm{CP}}$ of GFLV origin (43). Interestingly, the seven $X$. index lines used in this study efficiently transmitted this natural chimeric virus, confirming that gene $2 \mathrm{~B}^{\mathrm{MP}}$ is not involved in the specificity of transmission of GFLV by $X$. index.

The dynamic of GFLV spread by $X$. index in vineyards may differ from site to site (D. Esmenjaud, unpublished). These differences may be correlated to $X$. index-grapevine cultivar interactions, pedoclimatic characteristics acting on the dynamic of $X$. index populations (39), and differential GFLV transmission efficiency (12). Based on our findings, it seems that differences in GFLV spread in vineyards are more likely due to the dynamic of $X$. index populations in relation to crop management practices (45) and soil texture and moisture $(18,23)$, as well as host susceptibility and plant vigor (23).

Rouging is recommended to control GFLV in infected vineyards in combination with soil disinfection with nematicides and extended fallow (1). Agrochemicals are usually not efficient to control viruliferous nematode populations and constitute a hazard to the environment (1). Their use was restricted or banned recently in Europe $(21,22)$. Extended periods of fallow are difficult to implement for economic reasons, especially in premium vineyards. $X$. index-tolerant rootstocks have been developed. They reduce $X$. index numbers but do not prevent GFLV transmission $(5,20,47,48)$. Therefore, breeding programs are currently working to develop plant material resistant to $X$. index and GFLV (20). Our findings suggest that any $X$. index population should be suitable to evaluate plant reaction to virus infection following nematode transmission of GFLV. This should facilitate the screening of Vitis spp. for resistance to GFLV.

\section{ACKNOWLEDGMENTS}

This work was partially supported by a competitive grant from the European Commission (QLK3-CT-2002-02140), the Comite Interprofessionnel du Vin de Champagne (CIVC), the Comité Technique Permanent de la Sélection (CTPS), and the Département Santé des Plantes et Environnement of the Institut National de la Recherche Agronomique. We thank J. Philis (Cyprus), M. Di Vito (Italy), A. Walker (United States), D. Nevo (Israel), and M. Arias (Spain) for providing vineyard soil samples to establish $X$. index populations; and E. Duchene 
for advice with statistical analyses. This article is dedicated to the memory of Dr. Mike Mayo.

\section{LITERATURE CITED}

1. Andret-Link, P., Laporte, C., Valat, L., Ritzenthaler, C., Demangeat, G., Vigne, E., Laval, V., Pfeiffer, P., Stussi-Garaud, C., and Fuchs, M. 2004. Grapevine fanleaf virus: Still a major threat to the grapevine industry. J. Plant Pathol. 86:183-195.

2. Andret-Link, P., Schmitt-Keichinger, C., Demangeat, G., Komar, V., and Fuchs, M. 2004. The specific transmission of Grapevine fanleaf virus by its nematode vector Xiphinema index is solely determined by the viral coat protein. Virology 320:12-22.

3. Antoniou, M. 1989. Arrested development in plant parasitic nematodes. Helminthol. Abstr. Ser. B. 58:1-19.

4. Belin, C., Schmitt, C., Demangeat, G., Komar, V., Pinck, L., and Fuchs, M. 2001. Involvement of RNA2-encoded proteins in the specific transmission of Grapevine fanleaf virus by its nematode vector Xiphinema index. Virology 291:161-171.

5. Bouquet, A., Torregrosa, P., and Chatelet, P. 2004. Combinaison des approches biotechnologiques et conventionnelles dans la sélection de porte-greffes présentant une résistance durable à la transmission de la maladie du court-noué. Bull. O.I.V. 77 (879-880):361-376.

6. Brown, D. J. F. 1985. The transmission of two strains of strawberry latent ringspot virus by populations of Xiphinema diversicaudatum (Nematoda: Dorylamoidea). Nematol. Mediterr. 13:217-223.

7. Brown, D. J. F. 1986. The transmission of two strains of Arabis mosaic virus from England by populations of Xiphinema diversicaudatum (Nematoda: Dorylamoidea) from ten countries. Rev. Nematol. 9:83-87.

8. Brown, D. J. F. 1986. Transmission of virus by the progeny of crosses between Xiphinema diversicaudatum (Nematoda: Dorylaimoidea) from Italy and Scotland. Rev. Nematol. 9:71-74.

9. Brown, D. J. F., Kunz, P., Grunder, J., and Robertson, W. M. 1998. Differential transmission of cherry rosette nepovirus by populations of Longidorus arthensis (Nematoda:Longidoridae) with a description of the association of the virus with the odontostyle of its vector. Fundam. Appl. Nematol. 21:673-677.

10. Brown, D. J. F., and Trugdill, D. L. 1983. Differential transmissibility of arabis mosaic virus and strawberry latent ringspot virus by three populations of Xiphinema diversicaudatum (Nematoda: Dorylamoidea). Rev. Nematol. 6:229-238.

11. Brown, D. J. F., and Weischer, B. 1998. Specificity, exclusivity and complementarity in the transmission of plant viruses by plant parasitic nematodes: An annotated terminology. Fundam. Appl. Nematol. 21:1-11.

12. Catalano, L., Roca, F., and Castellano, M. 1989. Efficiency of transmission of an isolate of grapevine fanleaf virus (GFV) by three populations of Xiphinema index (Nematoda: Dorylaimida). Nematol. Mediterr. 17:13-15.

13. Catalano, L., Savino, V., and Lamberti F., 1992. Presence of grapevine fanleaf nepovirus in populations of longidorid nematodes and their vectoring capacity. Nematol. Mediterr. 20:67-70.

14. Catalano, L., Savino, V., Lamberti, F., and Martelli, G. P. 1991. Transmission of three isolates of grapevine fanleaf nepovirus to grapevine species and rootstock hybrids by two populations of Xiphinema index. Nematol. Mediterr. 19:349-351.

15. Coiro, M., Taylor, C. E., Borgo, M., and Lamberti, F. 1990. Resistance of grapevine rootstocks to Xiphinema index. Nematol. Mediterr. 18:119-121.

16. Dalmasso, A., and Younes, T. 1969. Ovogénèse et embryogénèse chez Xiphinema index (Nematoda: Dorylaimida). Ann. Zool. Ecol. Anim. 1:265-272.

17. Demangeat, G., Komar, V., Cornuet, P., Esmenjaud, D., and Fuchs, M. 2004. Sensitive and reliable detection of Grapevine fanleaf virus in a single Xiphinema index nematode vector. J. Virol. Methods 122:79-86.

18. Demangeat, G., Minot, J. C., Voisin, R., Bosselut, N., Fuchs M., and Esmenjaud, D. 2005. Survival of Xiphinema index and retention of Grapevine fanleaf virus over extended periods of time in the absence of host plants. Phytopathology 95:1151-1156.

19. Douglas, N., and Krüger, K. 2008. Transmission efficiency of Grapevine leafroll-associated virus 3 (GLRaV-3) by the mealybug Planoccous ficus and Pseudococcus longispinus (Hemiptera: Pseudococcidae). Eur. J. Plant Pathol. 122:207-212.

20. Esmenjaud, D., and Bouquet, A. 2009. Selection and application of resistant germplasm application for grapevine nematodes management. Pages 195-214 in: Integrated Management of Fruit Crops and Forest Nematodes. A. Ciancio and K. G. Mukerji, eds. Springer, Dordrecht, The Netherlands.

21. European Commission. 2003. Council Decision of 18 March 2003 concerning the non-inclusion of aldicarb in Annex I to Council Directive 91/414/EEC and the withdrawal of authorisations for plant protection products containing this active substance (2003/199/EC). Off. J. Eur. Union. L76:21-23.

22. European Commission. 2007. Council Decision of 20 September 2007 concerning the no inclusion of 1,3-dichloropropene in Annex I to Council Directive 91/414/EEC and the withdrawal of authorisations for plant protection products containing that substance (notified under document number C(2007) 4281). Off. J. Eur. Union L249:11-13.

23. Feil, H., Westerdahl, B. B., Smith, R. J., and Verdegaal, P. 1997. Effects of seasonal and site factors on Xiphinema index in two California vineyards. J. Nematol. 29:491-500.

24. Hooper, D. J. 1986. Extraction of free-living stages from soil. Pages 5-30 in: Laboratory Methods for Work with Plant and Soil Nematodes. J. F. Southey, ed. Ministry of Agriculture, Fisheries and Food, London.

25. Huss, B., Walter, B., and Fuchs, M. 1989. Cross-protection between Arabis mosaic virus and Grapevine fanleaf virus in Chenopodium quinoa. Ann. Appl. Biol. 114:45-60.

26. Kumar, V., Radha, A., and Kumar-Chitta, S. 1998. In vitro plant regeneration of fig (Ficus carica L. cv. gular) using apical buds from mature trees. Plant Cell Rep. 17:717-720.

27. Loof, P. A. A., and Luc, M. 1989. A revised polytomous key for the identification of species of the genus Xiphinema Cobb, 1913 (Nematoda: Longidoridae) with exclusion of the $X$. americanum group. Syst. Parasitol. 16:35-66.

28. Malan, A. P., and Meyer, A. J. 1993. Interaction between a South African population of Xiphinema index and different grapevine rootstocks. S. Afr. J. Enol. Vitic. 14:11-15.

29. Martelli, G. P. 1975. Some features of nematode-borne viruses and their relationships with the host plants. Pages 223-252 in: Nematode Vectors of Plant Viruses. F. Lamberti, C. E. Taylor, and J. W. Seinhorst, eds. Plenum, New York.

30. Mojtahedi, H., Sturhan, D., Akhiani, A., and Barroti, S. 1980. Xiphinema species in Iranian vineyards. Nematol. Mediterr. 8:165-170.

31. Ploeg, A. T., Robinson, D. J., and Brown, D. J. F. 1993. RNA-2 of tobacco rattle virus encodes the determinants of transmissibility by trichodorid vector nematodes. J. Gen. Virol. 74:1463-1466.

32. Raski, D. J., and Hewitt, W. M. 1960. Experiments with Xiphinema index as a vector of fanleaf of grapevines. Nematologica 5:166-170.

33. Raski, D. J., Hewitt, W. B., Goheen, A. C., Taylor, C. E., and Taylor, R. H. 1965. Survival of Xiphinema index and reservoirs of fanleaf virus in fallowed vineyard soil. Nematologica 11:349-352.

34. Ritzenthaler, C., Viry, M., Pinck, M., Margis, R., Fuchs, M., and Pinck, L. 1991. Complete nucleotide sequence and organization of grapevine fanleaf nepovirus RNA1. J. Gen. Virol. 72:2357-2365.

35. Serghini, M. A., Fuchs, M., Pinck, M., Reinbolt, J., Walter, B., and Pinck, L. 1990. RNA2 of grapevine fanleaf virus: Sequence analysis and coat protein cistron location. J. Gen. Virol. 71:1433-1441.

36. Sopp, E., Rühl, E. H., and Holst, H. 1998. Resistance of rootstocks to the virus transmitting nematode Xiphinema index. Vitic. Enol. Sci. 53:3-6.

37. Staudt, G. 1997. A quick-test for screening resistance to transmission of grapevine fanleaf virus by Xiphinema index. Vitis 36:155-156.

38. Symmes, E. J., and Perring, T. 2007. Intraspecies variation in Zucchini yellow mosaic virus transmission by Myzus persicae and the impact of aphid host plant. J. Econ. Entomol. 100:1764-1772.

39. Taylor, C. E., and Brown, D. J. F. 1997. Nematode vectors of plant viruses. In: Nematode Vectors of Plant Viruses. CAB International, Wallingford, UK.

40. Taylor, C. E., and Raski, D. J. 1964. On the transmission of grapevine fanleaf by Xiphinema index. Nematologica 10:489-495.

41. Torregrosa, L., and Bouquet, A. 1995. In vitro propagation of Vitis x Muscadinia hybrids by microcuttings or axillary budding. Vitis 34:237-238.

42. Vigne, E., Bergdoll, M., Guyader, S., and Fuchs, M. 2004. Population structure and genetic variability within isolates of Grapevine fanleaf virus from a naturally infected vineyard in France: Evidence for mixed infection and recombination. J. Gen. Virol. 85:2435-2445.

43. Vigne, E., Marmonier, A., and Fuchs, M. 2008. Multiple interspecies recombination events within RNA2 of Grapevine fanleaf virus and Arabis mosaic virus. Arch. Virol. 153:1771-1776.

44. Villate, L. 2008. Origine, variabilité et gestion des populations de Xiphinema index, le nématode vecteur du Grapevine fanleaf virus (GFLV). Ph.D. thesis, Université de Rennes 1, Rennes, France.

45. Villate, L., Fievet, V., Hanse, B., Delemarre, F., Plantard, O., Esmenjaud, D., and van Helden, M. 2008. Spatial distribution of the dagger nematode Xiphinema index and its associated Grapevine fanleaf virus in French vineyard. Phytopathology 98:942-948.

46. Vuittenez, A., Munck, M. C., and Kuszala, J. 1964. Souches de virus à hautes aggressivité isolées de vignes atteintes de dégénérescence infectieuse. Etudes Virol. Appl. 5:69-78.

47. Walker, A. 2006. New nematode-resistant grape rootstocks are nearing release. FPS (Foundation Plant Serv.) Grape Program Newsl. November 2006:8-10.

48. Walker, M. A., Wolpert, J. A., and Weber, E. 1994. Field screening of grape rootstock selections for resistance to fanleaf degeneration. Plant Dis. 78:134-136 